\title{
A educação 4.0: Um estudo de caso acerca da formação de professores para enfrentamento dos desafios do século XXI
}

\author{
Isadora Luiz Lemes*, Renato P. dos Santos ${ }^{\star \star}$
}

\section{Resumo}

Este artigo apresenta um Estudo de Caso realizado em uma oficina voltada a Formação de Professores ocorrida no segundo semestre de 2019. Diante das tantas transformações que vêm acontecendo e envolvendo inúmeros segmentos da sociedade, a Educação não pode ficar à margem e ignorar que há necessidade em delinear estratégias e metodologias para que os professores estejam preparados e obtenham adequada formação de modo que os discentes atuem, futuramente, de forma ativa e consonante às necessidades e realidades do século XXI. Esta proposta teve por objetivo propiciar um momento de formação para professores, de modo a discutir, de forma inicial, as mudanças que se fazem mister e o que vêm sendo previsto envolvendo a Educação 4.0, enfocando no modo como se poderia pensar em adotar novas posturas, dando espaço para que o docente pudesse repensar e refletir acerca de seu papel no momento atual, bem como, sobre quais serão suas competências no contexto atual. A oficina realizou-se no ambiente de uma Universidade e era aberta a todos os professores, independente se atuavam na Educação Básica ou superior, ou mesmo para alunos das licenciaturas, que podiam manifestar interesse em participar mediante inscrição prévia. Um participante manifestou interesse e compareceu e, por este motivo, este trabalho corresponde a um Estudo de Caso. Foram coletados dados de natureza qualitativa através de um questionário semiestruturado e, após, solicitou-se que o participante esboçasse um plano de aula em acordo com o que foi discutido no decorrer da oficina. O professor participante mostrou conhecimento e propriedade acerca do tema abordado e apontou que há necessidade em atribuir melhores condições às capacitações docentes.

Palavras-chave: Formação de Professores, Educação 4.0, Século XXI, Oficina, Formação Continuada.

\footnotetext{
* Mestra em Ensino de Ciências e Matemática pelo Programa de Pós - Graduação em Ensino de Ciências e Matemática na Universidade Luterana do Brasil (ULBRA). Doutoranda em Ensino de Ciências e Matemática no Programa de Pós-Graduação em Ensino de Ciências e Matemática da ULBRA. Brasil. E-mail: isa.ulbra@ hotmail.com

* Doutor em Física pelo Centro Brasileiro de Pesquisas Físicas. Professor adjunto no Programa de Pós-Graduação em Ensino de Ciências e Matemática da ULBRA. Brasil. E-mail: renatopsantos@ulbra.edu.br
}

Recebido em: 09/04/2020 - Aceito em: 29/01/2021

https://doi.org/10.5335/rbecm.v4i1.10842

http://creativecommons.org/licenses/by-nc-nd/4.0 


\section{Introdução}

É sabido que mesmo que o acesso à informação tenha se universalizado, ainda há muitas lacunas a serem preenchidas que demandam maiores discussões. Como exemplo, se pode mencionar o fato de que ainda é perceptível muita desigualdade em relação ao uso e implementação de tecnologias, tanto no cotidiano, quanto em relação às atividades voltadas ao aprendizado, sendo assim, é deveras importante que se considere discutir e pensar soluções para estas questões, sobretudo nos dias de hoje, em que nossa sociedade caminha em direção à avanços de cunho tecnológico cada vez mais perceptíveis.

Tais desigualdades, se evidenciaram fortemente devido a pandemia da COVID-19 (Dos SANTOS, BULBUL \& LEMES, 2020), o que mostra a importância de professores e alunos terem plasticidade para modificar práticas, quando desafios do tipo se apresentarem.

Estrada (2013, p. 54), trata que a educação necessita promover a análise de diferentes realidades possibilitando que os discentes tenham condições de discutir e construir seu posicionamento diante de determinadas situações através de bases conceituais sólidas. Acredita-se que, para que os alunos tenham condições de posicionar-se, é fundamental que os professores que os ensinam também saibam.

$\mathrm{O}$ autor supracitado, afirma que o atual modelo educacional, concebido em tempos antigos, não está adequado para que as crianças e jovens sejam educadas de acordo com a sociedade que os espera adultos amanhã. Portanto, é indispensável que o ensino seja ajustado às necessidades e objetivos que são considerados importantes agora (ESTRADA, 2013, p. 55).

Contudo, apesar de os governos seguirem propondo mudanças curriculares que visem a incorporação de tecnologias em ambientes escolares com o intuito de tornar o indivíduo proficiente nestas, a escola e o sistema como um todo, caminham na contramão da evolução e seguem primando pela produtividade. É importante destacar que se as escolas seguirem considerando pouco o processo criativo e espontâneo dos e das estudantes, poderão não estar contribuindo com habilidades que em breve serão exigidas como fundamentais, sobretudo em um mundo em que não sabemos mais quais profissões existirão ou mesmo quais surgirão (ESTRADA, 2013, p. 55).

Salmon (2019, p. 95), também tece comentários acerca da questão laboral dos tempos futuros e reconhece que as grandes transformações na educação ocorrem 
de forma lenta. $\mathrm{O}$ autor descreve ainda, em seu trabalho, as preocupações de estudantes do ensino superior quanto à qual papel exercerão no futuro que os aguarda.

Como posto nas Diretrizes Curriculares Nacionais (2013), apenas a escola não é capaz de cessar todas as desigualdades existentes, porém possui, como afirmado no documento, importante atuação na ampliação de condições que proporcionem aos indivíduos, inclusão social com acesso "à ciência, à tecnologia, à cultura e ao trabalho" (BRASIL, 2013, p. 167).

Uma das definições encontradas no documento da Base Nacional Comum Curricular (2017) trata dos desafios concernentes a garantir aprendizagens e permanência dos e das estudantes no Ensino Médio, de modo que sejam realizadas ações que vão ao encontro de suas pretensões presentes e futuras (BRASIL, 2017, p. 461).

$\mathrm{Na} \mathrm{BNCC}$, é citada a necessidade de preparação básica do sujeito para o trabalho e traz a importância do desenvolvimento de competências que promovam a inserção dos estudantes no Mercado de Trabalho, que vêm mostrando-se cada vez mais imprevisível.

Sendo assim, é dever da escola, segundo a BNCC (2017), entre suas tantas atribuições, preparar esses indivíduos para que possam inserir-se de forma criativa, crítica, ativa e, sobretudo responsável, com capacidade de resiliência que lhes permita fácil adaptação nos diferentes contextos que possam surgir e cabe também ao professor esta tarefa.

Segundo o documento da Base Nacional Comum Curricular (2017) os currículos e os Projetos Pedagógicos devem ser reestruturados para que assim se possa:

- explicitar que o trabalho produz e transforma a cultura e modifica a natureza;

- relacionar teoria e prática ou conhecimento teórico e resolução de problemas da realidade social, cultural ou natural;

- revelar os contextos nos quais as diferentes formas de produção e de trabalho ocorrem, sua constante modificação e atualização nas sociedades contemporâneas, em especial no Brasil; e

- explicitar que a preparação para o mundo do trabalho não está diretamente ligada à profissionalização precoce dos jovens - uma vez que eles viverão em um mundo com profissões e ocupações hoje desconhecidas, caracterizado pelo uso intensivo de tecnologias -, mas à abertura de possibilidades de atuação imediata a médio e a longo prazo e para a solução de novos problemas. 
Menezes (2009, p. 183) atenta para o fato de que, na prática, a educação carece de investimentos de longo prazo e isso exige que políticas de estado sejam criadas transcendendo os governos que passarem por nós (ROITMAN, 2009, p. 140), sobretudo se o país visa crescimento econômico estável e se almejarmos tornar a formação científica um bem atingível por todos, mesmo que haja ainda distribuição desigual de bens sociais, econômicos e culturais no Brasil.

Roitman (2009) destaca que:

Nesse novo contexto, cresce cada vez mais a importância do papel da educação e da pesquisa científica e tecnológica para atender às necessidades e oportunidades que se apresentam a cada momento. Os instrumentos criados pelas novas tecnologias dependem essencialmente de recursos humanos capacitados para acessar informações e transformá-las em conhecimento e inovação (ROITMAN, 2009, p. 135).

No intuito de tornar os sujeitos melhor preparados, é de extrema importância que a Educação Científica seja levada a sério e que para ela sejam traçados novos objetivos, métodos e estratégias de modo que se estruture sobre novos princípios que não se fixem em acreditar que o papel do professor é predominantemente o de transmissor do conhecimento e o do aluno de mero receptor (MENEZES, 2009, p. 186).

Neste sentido, é preciso que esteja em pauta de discussão modelos diversos de Formação de Professores, seja inicial ou continuada que atendam o bradar por profissionais melhor qualificados e que estejam aptos e dispostos à refletir sobre sua prática docente, visando traçar estratégias e delinear metodologias que possam servir como base, para que os alunos aprendam, estando em conformidade com a sociedade atual.

Apresentaremos aqui os dados, bem como, a análise dos mesmos, que foram observados em uma oficina constituída por um encontro presencial com duração de duas horas, que possui dados pouco representativos, já que o participante possuía conhecimentos na área e acredita na importância da Formação de Professores como forma de superar os desafios da Educação 4.0 na sociedade.

Justifica-se este trabalho por acreditarmos que, devido as tantas mudanças pelas quais a sociedade vem passando, promovidas por influência direta das tecnologias, é importante que possamos compreender nosso papel diante das transformações, para que assim, seja possível contribuirmos para a formação crítica e cidadã de nossos alunos.

Este trabalho está organizado, primeiramente em um aporte teórico que traz as Tecnologias e como se envolvem no contexto atual da educação, enfatizando o quão 
importante é o papel da formação docente neste contexto. Posteriormente, ainda na discussão teórica, abordamos a Educação 4.0 conceituando seu significado e quais impactos na Educação as transições podem provocar, pensando também em como afetarão os professores, que devem estar preparados para os desafios que surgirão em decorrência do surgimento de outras tecnologias que poderão ser adotadas na Educação.

\section{Tecnologias e o contexto atual da educação}

Entendemos que é muito importante que haja investimentos por parte dos governos acerca da formação dos professores para que estes, na condição de mediadores do conhecimento, saibam que atitude tomar em relação à sua prática, auxiliando seus alunos para que possam tornar-se aptos para os desafios que poderão encontrar.

Nós passamos por diversas mudanças no contexto da sociedade atual, o que vêm se mostrando uma constante na sociedade em si, essas mudanças, a princípio, sempre aconteceram e estiveram presentes, a diferença agora, está na intensidade, velocidade com que estas estão sendo percebidas.

Com tantas modificações ocorrendo e incluindo cada vez mais tecnologias digitais, é preciso que se entenda de onde os dados provêm, o que eles representam e como podem ser transformados em conhecimento a partir de informações para que, se tenha condições de resolver problemas de domínios diversos, pois não é suficiente que tenhamos diferentes aparatos tecnológicos, sem que saibamos como usar.

É fundamental que o Ensino de Ciências conte com professores qualificados e atualizados de acordo com aquilo que a sociedade necessita, para que, tanto eles quanto os discentes, exerçam sua cidadania na conjuntura atual e estejam preparados para atuar no modelo de sociedade que está se desenvolvendo.

A temática envolvendo Educação 4.0 para a Formação de Professores, apresenta assim, muitos desafios que segundo Nóvoa (1992) não estão apenas atrelados “à reciclagem dos professores, mas também à sua qualificação para o desempenho de novas funções" que transcendem hoje, apenas a de ensinar.

Frente às diferentes situações que acometem nossa sociedade, se percebe a importância de que se discuta o papel da educação científica no cenário atual e, deste modo, acreditamos no quão fundamental é contarmos com professores bem qualificados e que formem alunos capazes de enfrentar as transformações que ocorrem a todo o momento. 
O trabalho de da Silva e Correa (2014) discorre sobre a relação entre Educação e Tecnologias atuais, no processo do Ensino e da Aprendizagem em busca de reflexões pautadas nos desafios trazidos pela atualidade, sobretudo pelo intenso desenvolvimento tecnológico que vem ocorrendo nesta última década.

Neste atual contexto, de intensas transformações, vemos como é necessário discutir a prática docente em acordo com o que agora acontece, deste modo concordamos com Silveira e Bazzo (2009), que afirmam que é preciso que façamos uma avaliação crítica acerca das tecnologias, bem como, sua constituição histórica, sua função social, para que assim possamos não apenas buscar compreender o sentido da mesma, mas repensar o seu papel e no que influencia no contexto em que vivemos.

Neste sentido, é de suma importância pensarmos no porque formar e para que finalidade formar os discentes, ou para que usar e implementar tecnologias no processo de ensino e aprendizagem, visto que, pensar no ferramental, sem dúvida é importante, mas estender a compreensão acerca do que essas tecnologias representam para a sociedade também é fundamental.

Segundo da Silva e Correa (2014), ou os professores se adaptam às novas exigências da educação, ou poderão ser considerados ultrapassados. O que se pretende, não é necessariamente pressioná-los a isso, mesmo porque entende-se a forte demanda desta profissão que se encontra tão desvalorizada, mas a intenção, é sim, conscientizar os docentes de seu papel e do quanto devem atualizar sua prática.

Estrada (2013, p. 54) trata ainda, que a educação necessita promover a análise de diferentes realidades possibilitando que os discentes tenham condições de discutir e construir seu posicionamento diante de determinadas situações através de bases conceituais sólidas.

Para que isso seja possível, se entende o quanto é fundamental oferecer a formação necessária aos professores, de modo que possam ter condições de formar os educandos para uma sociedade que exige cada vez mais conhecimentos que não estão sendo incluídos e desenvolvidos, devido ao modelo de escola que ainda vigora.

\section{A educação 4.0: as não tão novas habilidades de um professor}

Há algum tempo, começamos a perceber discussões acerca da Educação $4.0 \mathrm{e}$ o que dela se espera ao que se refere à construção do indivíduo quanto cidadão e como impactará na atuação do mesmo em seu meio. O termo/conceito de Educação 
4.0, passa a ser falado após conhecermos a Indústria 4.0 e o que nela está implementado, bem como, suas necessidades, visto que está amplamente conectada ao processo educacional, já que os futuros trabalhadores, seguramente, encontrarão um panorama diferente do atual.

$\mathrm{E}$, obviamente, esses impactos não vão apenas passar pela educação, mas atingirão, querendo ou não, o modo como enxergamos este processo de formar indivíduos, prepará-los e promovê-los à sociedade. E, por este motivo, surgem discussões acerca da Educação 4.0, que é considerada por pesquisadores como a resposta às necessidades da indústria 4.0.

Quanto às transformações e inovações, percebemos que estas trazem muito o que se pensar e isso não é exclusividade de agora, pois pelo que se sabe é algo que perpassa as sociedades desde que se consegue identificá-las e as que vemos agora também vão impactar profundamente os docentes, em decorrência do que ocorre na sociedade também.

Salmon (2019, p. 97), descreve as definições de Educação que antecederam a Educação 4.0, nomeando cada uma delas, respectivamente, como, Transmissão, Social e Vidas Digitais e, enfatiza que há um elo da Educação para Indústria e empregabilidade, que nos faz perceber o quanto uma coisa está conectada a outra. Sendo assim, não pensar no modelo de educação que esteja de acordo com a sociedade atual, pode provocar impactos nocivos em diferentes aspectos sociais e econômicos.

De acordo com Fisk (2017, tradução nossa), a Educação 4.0 trata-se de uma resposta às premências da Indústria 4.0, em que humanos não serão substituídos por máquinas, mas sim, irão aliar-se as mesmas no intuito de trazer novas possibilidades, concernentes às diferentes atividades que envolvem aspectos da vida humana.

Fisk (2017, tradução nossa) afirma que a Educação 4.0, aproveita também 0 potencial de diferentes tecnologias, dados personalizados - que são colhidos de usuários - e conteúdo de código aberto, bem como, estabelece planos para o futuro da aprendizagem, que não restringe-se apenas a espaços escolares formais, mas também à aprendizagem contínua no local de trabalho, que exigirá postura flexível dos indivíduos, independendo de suas profissões.

Ao falar de uma definição para a Educação 4.0, Fisk (2017, tradução nossa), destaca aspectos como saber o porquê precisamos de algo, seja conhecimento ou habilidade, para depois saber onde encontrá-los, deste modo, não sendo necessário, 
aprender acerca de tudo, pois teríamos condições de buscar o que precisamos através de caminhos que poderíamos delinear.

Quanto a aprender acerca de tudo, imagina-se que a imensa maioria não consegue absorver totalmente os conteúdos trabalhados, de todas as áreas que subdividem o aprendizado nas escolas. Deste modo, currículos pensados de forma estratégica, atendendo características mais individuais, podem ser mais atrativos.

$\mathrm{O}$ autor supracitado, apresenta nove tendências da educação no século XXI e, uma delas, está diretamente relacionada à figura do professor, se referindo à tutoria que se tornará fundamental, devendo ser incorporada nos atuais processos de aprendizagem, no intuito de mediar as tantas informações, nem sempre fidedignas, que os alunos poderão estar submetidos.

$\mathrm{E}$ o momento atual não deixa dúvidas de que o professor tem extrema importância no movimento de aprendizagem dos discentes, visto que, estes profissionais, figuram como os mais qualificados para auxiliar na elucidação de dúvidas e no esclarecimento de informações incorretas.

Os professores 4.0, figurariam como facilitadores, indivíduos que não apenas sabem sobre algo, mas também deixam espaço para sua aprendizagem, estimulam alunos a colaborarem entre si, sem competição exacerbada, mas sim, com trabalho em equipe buscando alcançar soluções para problemas comuns.

Contudo, as demais tendências são também da incumbência do professor, apesar de estarem se referindo ao aprendizado dos alunos, é preciso que, os professores assumam o papel de facilitadores para que os alunos saibam como desenvolver seu aprendizado baseados na oportunidade de aprender a qualquer momento no local em que estiverem, tendo garantido o direito de aprender de forma individual em acordo com seus objetivos e interesses.

Com a iminente necessidade de os alunos estarem cada vez mais preparados para as mudanças que vêm ocorrendo, uma alternativa aos conhecidos modelos de aprendizagem seria aliar atividades envolvendo metodologias ativas, promovendo a capacitação dos jovens para um mundo do trabalho, adequando as exigências que podem surgir, além das diferentes competências que podem ser requisitadas.

Muitos professores têm potencial para atuar através da adoção de novas metodologias, como exemplo, podemos mencionar as Metodologias Ativas, tão estimadas atualmente, como vemos no trabalho de Morán (2015) mas deve-se considerar que estas não são exatamente novas - analisando temporalmente - o que pode abrir 
espaço para discutir os motivos pelos quais ainda não foram implementadas pela maioria das instituições.

Exemplificamos aqui as Metodologias Ativas, devido ao fato de que na oficina enfatizamos esta prática para nortear a atividade proposta ao participante, contudo, Educação 4.0 não se limita às Metodologias Ativas, portanto, estas configuram-se apenas como uma das tantas abordagens que podem ser percebidas e implementadas.

Neste sentido, cabe afirmar que a Educação 4.0, prima pela colaboratividade entre os indivíduos de maneira que isto facilite a interação deles, bem como, a capacidade de pensar em equipe, estratégias e soluções para problemas reais, ao contrário do que vemos em formatos que a antecedem.

Como exemplo de Metodologias Ativas, podemos citar a Aprendizagem Baseada em Problemas, que trata-se de um método que se caracteriza pelo uso de problemas do mundo real como base para encorajar os alunos a pensar criticamente e desenvolver habilidades voltadas a solução de problemas, facilitando assim, a construção de conhecimento da área em questão (RIBEIRO; ESCRIVÃO FILHO; MIZUKAMI, 2003).

O Estudo de Caso aplicado em atividades de sala de aula, é mais uma das estratégias que pode ser adotada para que se obtenha aprendizagem ativa, pois apresenta algo que deve ser solucionado exigindo empenho dos alunos que estão envolvidos para tal. Segundo Spricigo (2014), "o estudo de caso envolve a abordagem de conteúdo por intermédio do estudo de situações de contexto real" e estas situações denominam-se casos. Para a autora, uma das maiores riquezas desta abordagem é justamente a interação que ocorre entre os estudantes durante a investigação que se propõe.

Outro tipo de Metodologia Ativa que se pode adotar é a Aprendizagem entre pares, ou Peer Instruction, desenvolvida por Eric Mazur (1990) e que, segundo Muller, Araújo, Veit e Schell (2017) é uma metodologia centrada no estudante, que possibilita engajamento entre os sujeitos no momento da aprendizagem, e fortalece a aprendizagem conceitual permitindo ao indivíduo, ser capaz de desenvolver habilidades sociais e cognitivas. Esta é, portanto, uma Metodologia que permite aos jovens colaborarem entre si conjuntamente com seus pares.

Fala-se das novas competências e habilidades que devem ser incorporadas pelos professores, contudo, é válido questionarmos de até que ponto estas são realmente novas e, em que sentido de novo estamos nos referindo. Como se pode observar, contribuir para a construção de um Professor 4.0, não é uma questão de fácil resolução, é necessário compreender além do exercício profissional e buscar entendimento 
acerca do que o docente espera para si, visto que a maneira que deseja ser visto, pode impactar no modo como este atua em sala de aula e em que metodologias adota.

\section{Metodologia}

A estratégia de pesquisa escolhida neste contexto foi Estudo de Caso, em que se busca compreender o que pensa um professor específico já com elevada formação e com experiência no tema, a respeito de como devem ser conduzidas formações de professores que preparem para o momento atual.

De acordo com Yin (2001, p. 21), "um estudo de caso é uma investigação empírica que investiga um fenômeno contemporâneo dentro de seu contexto da vida real, especialmente quando os limites entre o fenômeno e o contexto não estão claramente definidos", entendemos que, nesta investigação, especificamente, não isolamos nem distanciamos o professor participante de seu contexto, visto que no decorrer da oficina, o mesmo teve de pensar sua prática e sugerir plano de aula em acordo com a temática que se estava abordando.

Inicialmente, pautou-se a oficina com fala expositiva que foi o momento em que se socializou com o participante os objetivos em que ela estava fundamentada, que eram:

- Contribuir mutuamente para a formação continuada e inicial,

- Propiciar discussões entre docentes de diferentes realidades

- Discutir colaborativamente acerca das mudanças da educação

- Repensar ações e estratégias que sejam capazes de modificar o espaço de atuação profissional

- Produzir conteúdo que nos faça refletir acerca de nosso papel frente as transformações.

Quanto aos instrumentos de coleta utilizados, optamos por coletar dados durante a oficina, pensando como forma de atividade algo que promovesse o repensar da prática, e esta consistiu em propor uma aula orquestrada nos princípios discutidos anteriormente que estivesse baseada na Educação 4.0.

Deste modo, as discussões que antecederam a atividade com o participante, pautaram-se em apresentar a temática inicialmente, tecendo comentários sobre $\mathrm{e}$ abrindo espaço para que o professor fizesse o mesmo. Discutimos acerca das tendências apontadas por Peter Fisk, bem como sobre alguns aplicativos que poderiam 
ser incorporados em atividades de aula conectados à Educação 4.0. A atividade principal, consistiu no participante criar um plano de aula inspirado em práticas que estivessem relacionadas aos tópicos abordados e que pudesse ser identificado como parte da Educação 4.0.

Ao final da oficina e como forma de feedback, entregamos um questionário semiestruturado ao participante, com cerca de vinte questões abertas e fechadas, em que ele pode descrever o que achou da oficina. A devolutiva do participante, auxiliaria a decidir o que poderia ser mantido e o que deveria ser incorporado em formatos de oficina futuros, visando propiciar um momento de ainda mais proveito, tanto aos participantes quanto aos pesquisadores.

Escolhemos basearmos em uma Metodologia Ativa para propormos a atividade ao professor na oficina, e, para isso, criamos duas situações problema como gatilho que antecedia a efetiva criação do plano de aula, que seria realizado logo após. Na Figura 1, podemos ver ambas situações.

Figura 1: Situações problema apresentadas ao professor participante

\section{Situação 1}

Enquanto você está

ministrando sua aula, percebe

que seus alunos prestam

muito mais atençẩo no celular

do que no conteúdo ou

mesmo no que é explicado. $\mathbf{O}$

que você pensarialusaria

como estratégia em suas

próximas abordagens?

\section{Situação 2}

Em 2016, Vanderlei Martinianos, um declarado "futurista da educaçăo" afirmou que em um futuro nåo muito distante, os professores serāo hologramas que estarão disponiveis a seus alunos para que estes possam aprender a qualquer momento. Dentro deste contexto, descreva como vocet imagina sua profísstio nos próximos anos.

Fonte: Os autores.

Tentamos propor situações problema que estivessem relacionadas ao que vemos agora como possíveis situações que serão vivenciadas pelos professores, sendo entregue ao participante uma folha para que pudesse organizar uma proposta didática/ plano de aula consonante às necessidades da Educação 4.0. 
A atividade deveria conter um Tema, Objetivo, Conteúdo a ser trabalhado, apresentar recursos que seriam utilizados, bem como a metodologia adotada. Após, iríamos discutir as respostas dele, debatendo suas escolhas e como ele as defendia. Os resultados e o plano construído pelo participante encontram-se no próximo tópico.

\section{Resultados e discussão}

Apresentaremos os dados coletados do questionário final antes da atividade desenvolvida, visto que neste questionário continham informações que caracterizam o participante e sua qualificação, que nos fazem compreender o nível de seu entendimento acerca do tema abordado.

O participante possui bacharelado em Sistemas de Informação e experiência docente de vinte e nove anos, com nível de Pós-graduação em Doutorado. De acordo com ele, o que o levou a optar pela carreira docente foi a possibilidade de 'mudar o mundo pela educação' e considera que sua motivação atual em relação ao início da carreira é cada vez maior, em função de ver a possibilidade de contribuir para a formação de professores, que em geral estão 'defasados'.

Coloca que considera importante que os professores busquem formação continuada e acredita que a Educação, do modo que está, não supre as necessidades trazidas pela sociedade atual, destacando que, de sua parte, pode propor eventos e capacitações colaborativas sobre Educação 4.0, para que a Educação comece a mudar, afirmando também, que costuma participar de eventos científicos, envolvendo sua área de formação.

Quanto à questão acerca da implementação de tecnologias em sala de aula, ter capacidade de promover melhoras na aprendizagem dos alunos, o participante afirma que estas podem proporcionar 'interatividade e personalização', destacando que já costuma utilizar recursos tecnológicos em sala de aula, como, 'Gamificação, ambiente híbrido (Internet, Smartphone etc.)'.

O participante atribui insegurança aos professores que não fazem uso de tecnologias em sala de aula e aponta que o uso do celular 'deve ser explorado', visto que pode apresentar muitas potencialidades que contribuem para o aprendizado e, em grande parte é utilizado muito mais para fins de entretenimento.

Este posicionamento do docente é refletido na pesquisa realizada a partir da iniciativa do movimento "Todos Pela Educação" (MANARIN; BENATTI, 2017) em que foi investigado o que pensam os professores acerca de Tecnologia Digital 
em sala de aula. Os dados apontam algumas das atribulações que a Educação em rede pode causar na vida docente.

O resultado a que chegaram os pesquisadores, apontou que mais da metade dos entrevistados afirmam que utilizariam mais as tecnologias em sala de aula, caso isto não demandasse mais carga de trabalho, ao passo que também têm a concepção de que a incorporação de tecnologias diferentes pode aumentar a pressão do trabalho sobre eles (MANARIN; BENATTI, 2017).

Talvez se possa elucubrar que haja mais do que insegurança por parte dos professores, já que este discurso se fundamenta, visivelmente, na falta de preparo que enfrentam em suas formações iniciais e que prevalece quando já estão exercendo a profissão.

Mesmo quando se promove algum tipo de formação, há maior enfoque em como utilizar as tecnologias como ferramentas e não como propulsoras de ideias (MISHRA; KOEHLER, 2006, OLIVEIRA; HENRIQUES; GUTIÉRREZ-FALLAS, 2018) e neste atual contexto esta é uma das questões que devem ser repensadas.

Neste sentido, ele concorda plenamente, que os alunos de agora encontrarão a frente uma sociedade que exige competências que o modelo atual de escola não dá conta e é assertivo ao mostrar que compreende que, o fato de adotar tecnologias em sala de aula não significa estar modificando a metodologia de ensino.

Mostrando que está em busca de alinhar-se às novas necessidades da sociedade atual, o professor participante afirma que adapta metodologias de ensino que considera diferentes das que já são comumente utilizadas, dando destaque à Sala de aula Invertida, aprendizagem baseada em problemas, ou ainda, aprendizagem baseada em projetos.

Esta relação entre professores e tecnologias atuais é um dos pontos mais importantes a se considerar neste contexto que discutimos anteriormente no referencial teórico. Apesar de imaginarmos que não seja um diálogo fácil de abordar, devido à resistência que já é conhecida, é importante problematizar estas questões e compreender que estão imbricadas aos desafios que as transformações provocam, mesmo porque, para promover uma pequena mudança, é preciso o debate.

Em busca de compreender de que forma o professor entende o conceito de Educação 4.0, perguntamos a ele o que entendia por Educação 4.0, e obtivemos como resposta que a mesma se refere a 'inserir o aluno de forma participativa e ativa/ colaborativa no processo da construção de conhecimento e da aprendizagem', e esta resposta mostra que há concordância com o que nós entendemos por Educação 4.0, 
visto que em nossa concepção, não é apenas sobre incluir tecnologia em sala de aula, mas sim, trazer para o cotidiano dos estudantes o que eles precisam apreender dela que será essencial em seu futuro próximo.

Ao encontro disto, Alarcon et al. (2018), afirmam que este modelo de Educação será fundamentado na 'relação humana qualificada' com foco na aprendizagem que visa a formação integral do sujeito e complementam ainda que, "o uso efetivo das TIC, materiais e ferramentas de acesso aberto" possibilitam cada vez mais uma educação interconectada e integrada às mídias.

Quanto ao feedback, questionamos a expectativa do participante ao inscrever-se na oficina para avaliar quais suas pretensões e o que esperava encontrar, obtendo como resposta do mesmo que desejava 'conhecer e trocar experiências sobre o tema, ampliar meu networking de professores que trabalhem/pesquisem sobre o tema' e quanto as críticas, sugestões e o que, de fato, vivenciou, o mesmo diz que realizou 'ótimas trocas, acreditando que deve ser ampliado para que mais alunos e professores participem, inclusive alunos da graduação'.

Como tarefa oriunda da oficina, pedimos que o participante construísse um plano de aula que acreditasse estar em consonância com a sociedade 4.0 contendo um tema, objetivos conteúdo, recursos necessários, metodologia utilizada e avaliação.

Quadro 1: Etapas da Proposta Didática/ Plano de aula desenvolvidos pelo professor participante

\begin{tabular}{|c|c|}
\hline Tema & Educação 4.0 \\
\hline Objetivos & $\begin{array}{l}\text { Apresentar a evolução no contexto da sociedade desde a chamada } 1.0 \text { até a } 4.0 \text {, } \\
\text { relacionando as características das metodologias/estratégias educacionais que dão } \\
\text { suporte a estas evoluções da sociedade. }\end{array}$ \\
\hline Conteúdo & $\begin{array}{l}\text { Evolução histórica da sociedade } \\
\text { Evolução das estratégias Educacionais }\end{array}$ \\
\hline $\begin{array}{l}\text { Recursos } \\
\text { necessários }\end{array}$ & Internet, Computadores ou Smartphones \\
\hline Metodologia & $\begin{array}{l}\text { 1) Problema/Desafio } \\
\text { 2) Conteúdo/Suporte } \\
\text { 3) Atividade Prática } \\
\text { 4) Socialização/Avaliação }\end{array}$ \\
\hline Desenvolvimento & $\begin{array}{l}\text { 1) Conduzir os alunos a refletir sobre hábitos e características da sociedade atual, } \\
\text { de modo a questionar se as práticas pedagógicas atendem esse público. Conduzir a } \\
\text { turma a sugerir um problema a ser resolvido. } \\
\text { 2) Provocar a turma a buscar diferentes fontes de informação sobre o perfil da socie- } \\
\text { dade e sobre a evolução da educação mediar os conteúdos /materiais em termos de } \\
\text { cientificidade e relevância. } \\
\text { 3) Em pequenos grupos (ou pares) os alunos devem criar/propor estratégias p/ traba- } \\
\text { lhar com Ed } 4.0\end{array}$ \\
\hline Avaliação & $\begin{array}{l}\text { 1) Socializar as atividades / trabalhos, possibilitando uma autoavaliação, avaliação } \\
\text { pelos colegas e constante avaliação online para outras pessoas. }\end{array}$ \\
\hline
\end{tabular}

Fonte: Os autores. 
Como tema, o professor escolheu Educação 4.0, para discutir a evolução histórica da sociedade, bem como, as estratégias educacionais que a marcam em diferentes momentos. Os recursos escolhidos, como se pode notar, não são em grande parte, difíceis de serem incorporados, sobretudo pelo fato de incluir Smartphones como ferramenta, o que praticamente todos os sujeitos possuem atualmente.

Os procedimentos metodológicos que o professor participante pensou em adotar, indicam o recurso de Metodologias ativas como estratégia, visto que, utilizou os termos 'problema' e 'desafio'; aqui fica aparente também que o mesmo assumiria postura de mediador, pelo fato de mencionar o termo 'suporte' no momento que sugere ser o desenvolvimento da atividade pelos indivíduos alvo de sua aula, a princípio, fictícia.

Com respeito a avaliação que escolheu adotar, é interessante a questão de inserir a socialização das produções dos indivíduos a seus pares, visto que este é um momento muito enriquecedor e de grandes contribuições, tanto do ponto de vista individual, quanto coletivo, pois ao se expor escutamos a nós mesmos e isto promove auto-observação o que permite avaliar se as medidas adotadas são as melhores, ou se podem ser aperfeiçoadas, inclusive com a sugestão dos outros partícipes.

O professor que participou desta pesquisa, demonstra conhecimentos acerca de Educação 4.0 e possui domínio quanto ao que se trata. Vemos que suas colocações concordam com a literatura abordada aqui, sobretudo pelo fato de entender como estratégias possíveis a adoção de solução de problemas reais a serem tratados pelos alunos e acreditar na importância da formação de professores.

Fica evidenciado que defende que os modelos de formação devem ocorrer de modo que os professores possam desenvolver sua prática em sentido de tornar seus alunos aptos a construir seu conhecimento de forma significativa e não mais primar pela postura reprodutiva que está a tanto tempo instaurada em nossas escolas e universidades.

\section{Considerações}

Entendemos que este estudo de caso foi deveras enriquecedor e reconfortante, visto que, sabermos que há professores interessados na temática 4.0, de modo a desejar contribuir com mudanças que façam desta, um modelo que possa ser seguido, sobretudo por entendermos que é possível envolver-se com Educação 4.0, inovando e criando a partir de recursos mais simples. 
Entendemos que a formação de professores deve ocorrer de modo a capacitar profissionais que saibam como superar desafios diversos que possam surgir em suas trajetórias como docentes e não para fazer com que reproduzam em suas salas de aula o que foi abordado durante a formação, mesmo porque, seria muito limitante se o que é para ser capacitação, fosse visto deste modo. É preciso abandonar a zona de conforto.

A oficina realizada tinha como principal intuito promover espaço para sensibilizar os professores acerca de iminentes mudanças que irão, mais cedo ou mais tarde, afetar sua atuação profissional, bem como, trocar informações, promover espaço para diálogo e contribuição mútua entre professores que conhecem a realidade de sala de aula, professores ainda em formação e professores pesquisadores.

Há alguns infortúnios que podemos pontuar aqui como possíveis problemas enfrentados e, o mais expressivo, certamente refere-se ao fato da baixa adesão às oficinas. Infortunadamente, não podemos afirmar o motivo da pouca procura; contudo, fazendo o mea culpa, reconhecemos que poderia ter ocorrido maior divulgação, para assim, conquistar maior número de participantes, aumentando a produção e trocas de ideias.

Quanto aos objetivos da oficina, dos cinco demarcados, consideramos que atingimos três, que foram: Discutir colaborativamente acerca das mudanças da educação, Repensar ações e estratégias que sejam capazes de modificar o espaço de atuação profissional e Produzir conteúdo que nos faça refletir acerca de nosso papel frente as transformações.

Não afirmamos com veemência que estes foram atingidos apenas pelo fato de 0 participante possuir conhecimento e domínio acerca do tema que foi tratado, mas sabe-se que o fato de ele ter propriedade da temática e mostrar-se um professor reflexivo que busca aprimorar sua prática, contribuiu para os bons resultados deste trabalho.

As limitações encontradas que foram descritas, não atrapalharam o andamento da oficina, mas, obviamente a presença de mais professores de diferentes níveis de formação proporcionaria debates mais intensos, de modo que estes trariam suas experiências cotidianas, exporiam dificuldades, práticas adotadas e teriam oportunidade de conhecer, talvez, estratégias diferentes das que estão acostumados.

Consideramos importante a divulgação massiva de eventos como este, visando atingir maior número de participantes. Se feito assim, acreditamos que os demais 
objetivos que traçamos, seriam provavelmente alcançados e possibilitariam maior quantidade de dados para análise.

Esta oficina foi desenvolvida em outubro de 2019, antecedendo, portanto, a pandemia que exigiu dos professores, alunos e gestores, adaptações imediatas, sem muito tempo para que pudessem se preparar e pensar em como lidar com os desafios propostos. Por estas e outras razões, reforçamos a importância de que haja investimento em formação de professores, justamente para superar obstáculos que possam surgir e que nem sempre estão relacionados aos acontecimentos trágicos que estamos vivenciando.

\section{Education 4.0: a case study on teacher education to face the challenges of the 21st century}

\section{Abstract}

This article presents a Case Study carried out in a workshop aimed at Teacher Education that took place in the second semester of 2019. In view of the many transformations that occur and involving numerous segments of society, Education cannot be left out and ignore the need to outline strategies and methodologies so that teachers are prepared and get trained so that students act, in the future, actively and in line with the needs and realities of the 21 st century. This proposal aimed to provide a moment of training for teachers, in order to discuss, in an initial way, how changes that are necessary and which are foreseen involving Education 4.0, focusing on how one could think about adopting new attitudes, giving space for the teacher to rethink and reflect on his role in the current moment, as well as, on what will be his skills in the current context. The workshop was held in a university environment and was open to all teachers, regardless of whether they worked in Basic Education or higher, or even for undergraduate students, who could express an interest in participating by prior registration. One participant expressed interest and attended and, for this reason, this work corresponds to a Case Study. Qualitative data were collected through a semi-structured questionnaire and, afterwards, the participant was asked to draft a lesson plan in accordance with what was discussed during the workshop. The participating teacher and knowledge about the topic addressed and pointed out that there is a need to assign the best conditions to teacher training.

Keywords: Teacher Education, Education 4.0, 21st Century, Workshop, Continuing Education.

\section{Agradecimentos}

Agradecemos à Coordenação de Aperfeiçoamento de Pessoal de Ensino Superior/ CAPES pela Bolsa concedida. 


\section{Referências}

ALARCON, D. et al. Os Desafios da Educação em rede no contexto da Indústria 4.0. In: VIII CONGRESSO INTERNACIONAL DE CONOCIMIENTO E INNOVACÍON, 2018, Guadalajara. Anais... . Guadalajara, 2018. p. 1 - 15.

BRASIL. Ministério da Educação. Conselho Nacional de Educação. Diretrizes curriculares nacionais para o ensino médio. Brasília: MEC/CNE, 2013.

BRASIL, Ministério da Educação. Secretaria de Educação Básica. Base Nacional Comum Curricular. Brasília: Ministério da Educação e da Cultura, 2017. Disponível em: <http://portal.mec. gov.br/index.php?option=com_docman\&view=download\&alias=79601-anexo-texto-bncc-reexportado-pdf-2\&category_slug=dezembro-2017-pdf\&Itemid=30192>. Acesso em: 28 ago. 2018.

ESTRADA, M. R. B. Nuevos valores para una nueva sociedad: un cambio de paradigma en educación. Edetania: estudios y propuestas socio-educativas, Valência, n. 43, p.53-65, abr. 2013.

FISK, P.. Education 4.0 ... the future of learning will be dramatically different, in school and throughout life. 2017. Disponível em: <https:/www.thegeniusworks.com/2017/01/future-education-young-everyone-taught-together/>. Acesso em: 12 out. 2018.

MANARIN, A.; BENATTI, B. O que pensam os professores brasileiros sobre a tecnologia digital em sala de aula? 2017. Disponível em: <https://www.todospelaeducacao.org.br/conteudo/O-que-pensam-os-professores-brasileiros-sobre-a-tecnologia-digital-em-sala-de-aula/>. Acesso em: 20 nov. 2018.

MENEZES, L. C. de. Cultura científica na sociedade pós-industrial. In: WERTHEIN, Jorge; CUNHA, Célio da. Ensino de Ciências e Desenvolvimento: O que pensam os cientistas. 2. ed. Brasília: Instituto Sangari, 2009. Cap. 18. p. 181-187.

MISHRA, P.; KOEHLER, M. J. Technological Pedagogical Content Knowledge: A Framework for Teacher Knowledge. Teachers College Record, Nova Iorque, v. 108, n. 6, p.1017-1054, jun. 2006.

MORÁN, J. Mudando a educação com metodologias ativas. Coleção Mídias Contemporâneas. Convergências Midiáticas, Educação e Cidadania: aproximações jovens, v. 2, p. 15-33, 2015.

MÜLLER, M. G.; ARAUJO, I. S.; VEIT, E. A.; SCHELL, J. Uma revisão da literatura acerca da implementação da metodologia interativa de ensino Peer Instruction. Revista Brasileira de Ensino de Física, São Paulo, v. 39, n. 3, mar. 2017.

NÓVOA, A. A Formação de professores e profissão docente. In: NÓVOA, A. Os professores e a sua formação. Lisboa: Publicações Dom Quixote, 1992. p. 13-33.

OLIVEIRA, H.; HENRIQUES, A.; FALLAS, L. F. G. A integração da tecnologia na planificação de aulas na perspectiva do ensino exploratório: um estudo com futuros professores de matemática. Revista do Centro de Ciências da Educação, Florianópolis, v. 36, n. 2, p.421-446, jun. 2018.

RIBEIRO, L. R. de C.; ESCRIVÃO FILHO, E.; MIZUKAMI, M. da G. N. Aprendizagem baseada em problemas (PBL): uma experiência no ensino de engenharia sob a ótica dos alunos. Revista de Ciências Humanas, Viçosa, MG, v. 3, n. 2, p. 95-101, 2003.

ROITMAN, I. Ciência para os jovens: falar menos e fazer mais. In: WERTHEIN, Jorge; CUNHA, Célio da. Ensino de Ciências e Desenvolvimento: O que pensam os cientistas. 2. ed. Brasília: Instituto Sangari, 2009. Cap. 12. p. 133-143. 
SALMON, G.. May the Fourth Be with You: Creating Education 4.0. Journal Of Learning For Development. United Kingdom, p. 95-115. fev. 2019.

SILVA, R. F; CORREA, E. S.. Novas Tecnologias e Educação: A Evolução do Processo de Ensino e Aprendizagem na Sociedade Contemporânea. Educação \& Linguagem, São Paulo, v. 1, n. 1, p. 23-35, jun. 2014.

SILVEIRA, R. M. C. F.; BAZZO, W. Ciência, tecnologia e suas relações sociais: apercepção de geradores de tecnologia e suas implicações na educação tecnológica. Ciência \& Educação, v. 15, n.3, p. 681-694. 2009.

SPRICIGO, C. B.. Estudo de caso como abordagem de ensino. 2014. Disponível em: https:// www.pucpr.br/wp-content/uploads/2017/10/estudo-de-caso-como-abordagem-de-ensino.pdf. Acesso em: 14 mar. 2020.

YIN, R. K.. Estudo de Caso: planejamento e métodos. 2. ed. Porto Alegre: Bookman, 2001. Tradução Daniel Grassi. 